\title{
Utilização terapêutica das células progenitoras adultas multipotentes alogênicas em cães acometidos pela doença renal
}

\author{
[Therapeutic use of allogeneic multipotent adult progenitor cells in dogs affected by renal disease]
}

\section{"Artigo Científico/Scientific Article"}

\author{
Enrico Jardim Clemente Santos ${ }^{1 *}$, Caroline Pinho Winck ${ }^{2}$, Camila Landim Braga ${ }^{3}$
}

\author{
${ }^{1}$ Departamento de Inovação Tecnológica, CELLTROVET, São Paulo-SP, Brasil. \\ ${ }^{2}$ Laboratório de Biotecnologia, CELLTROVET, São Paulo-SP, Brasil. \\ ${ }^{3}$ Departamento Clínico, CELLTROVET, São Paulo-SP, Brasil. \\ *Autor para correspondência/Corresponding author: E-mail: enricosantos@celltrovet.com.br
}

\begin{abstract}
Resumo
A doença renal crônica tem grande importância na medicina veterinária, pois representa grande casuística na clínica de pequenos animais, não possuindo perspectiva de cura até o momento. Esta síndrome se caracteriza pelo comprometimento do metabolismo renal, que ocorre de forma dinâmica e progressiva por períodos que variam de meses a anos, culminando na perda das funções fisiológicas dos rins. Atualmente, o tratamento inclui fluidoterapia, orientação dietética, diálise e tratamento sintomático paliativo, os quais visam prover uma melhora na qualidade de vida dos pacientes. Neste estudo, 12 cães sem distinção de raça e sexo, com idades entre 3 e 11 anos, acometidos pela doença renal crônica, estágio dois, foram tratados com células progenitoras adultas multipotentes, oriundas da gordura de animais doadores saudáveis. Foram realizadas três aplicações pela via endovenosa, com intervalo médio de 30 dias. Todos os pacientes demonstraram uma melhora significativa da função renal após as infusões das células progenitoras adultas multipotentes alogênicas de tecido adiposo de caninos, sem aparentes efeitos adversos. Foi observada uma melhora clínica, ganho de apetite e aumento da disposição em todos os pacientes já após a primeira aplicação. Conclui-se que a terapia com células progenitoras adultas multipotentes colaboraram significativamente para a melhoria da qualidade de vida dos cães acometidos pela doença renal crônica, estágio 2 .
\end{abstract}

Palavras-chave: células-tronco; lesão renal; canino; terapia celular.

\begin{abstract}
Chronic kidney disease, or chronic kidney failure, is of great importance in canine veterinary medicine because of the widespread incidence and lack of prospective cure at the moment. This syndrome is characterized by compromised function of the kidney metabolism, which occurs progressively over the course of months to years, culminating in the loss of physiological kidney function. Presently, therapies include rehydration, nutritional orientation, and dialysis, which seek to improve the quality of life of animals. In this study, 12 dogs of unidentified breeds, between 3 and 11 years of age, affected by stage 2 chronic kidney disease, were treated with multipotent adult progenitor cells from the fat of a healthy donor animal. Three intravenous applications with intervals of 30 days were administered. All the animals demonstrated a significant improvement in kidney function after the applications of allogenic multipotent adult progenitor cells without apparent adverse effects. All animals saw increased appetite, improved clinical appearance and a general improvement of disposition after only the first application. In conclusion, treatment with multipotent adult progenitor cells aided with a significant improvement of life for the affected canines diagnosed with stage 2 chronic kidney disease.
\end{abstract}

Keywords: Stem cell; renal injury; canine; cell therapy. 


\section{Introdução}

A doença renal, uma síndrome de alta incidência em cães, é a responsável por ocasionar elevados índices de morbidade e mortalidade (Grauer, 2005). Esta síndrome se caracteriza pelo comprometimento do metabolismo renal, o qual ocorre de forma dinâmica e progressiva, por períodos que variam de meses a anos, culminando na perda das funções fisiológicas dos rins (Pressler, 2013). Dados demonstraram que o rim é responsável por filtrar o sangue, a fim de excretar resíduos metabólicos e liberar hormônios que têm papel vital no controle da pressão arterial sistêmica e na produção de glóbulos vermelhos (Pressler, 2013).

As terapias convencionais, fluidoterapia, orientação dietética e diálise visam prover uma melhora na qualidade de vida dos pacientes. Entretanto, mesmo utilizando-se terapias conservativas, a injúria estrutural tende a evoluir, favorecendo a redução da massa renal e consequentemente a falência do órgão (Castro, 2005).

Embora fundamental, são baixos os índices de diagnóstico na fase inicial da doença renal, pois a manifestação dos sinais clínicos característicos tende a ocorrer em estágios mais avançados da doença. Devido aos aspectos restritivos, o prognóstico a longo prazo tem se mostrado desfavorável (Barber, 2003). Na medicina veterinária busca-se um tratamento que, juntamente com a terapia convencional, possa ser mais efetivo, melhorando a qualidade de vida e aumentando a sobrevida destes pacientes.

A doença renal (DR) pode ser classificada em insuficiência renal aguda (IRA) ou insuficiência renal crônica (IRC). A IRA é caracterizada pela rápida perda da função dos néfrons, resultando em azotemia e/ou aparecimento de alterações em fluidos e eletrólitos por meio da diminuição do fluxo sanguíneo intra-renal e danos celulares (Etiinger et al., 2017). Já a IRC apresenta lesões irreversíveis e progressivas que tornam o rim incapaz de realizar suas funções. $\mathrm{O}$ ritmo de progressão depende da doença original e causas agravantes como hipertensão, infecção urinária, nefrite, diabetes, dentre outras (McGrotty, 2008). A padronização das lesões renais levou a Sociedade Internacional de Interesse Renal (International Renal Interest Society - IRIS) a propor um sistema de classificação composto por quatro estágios, os quais são amplamente utilizados pela comunidade médica veterinária (http://www.iris-kidney.com/education/stagingsystem.shtml).

O estágio I da doença renal crônica é definido como um estado não azotêmico podendo apresentar alterações como inabilidade renal de concentração urinária, proteinúria renal e alterações renais ao exame de imagem e biópsia. O estágio II caracteriza-se pela presença de discreta azotemia em avaliações seriadas (creatinina sérica entre $1,4-2,0 \mathrm{mg} / \mathrm{dL}$ para cães e de $1,6-2,8 \mathrm{mg} / \mathrm{dL}$ para gatos). Pacientes no estágio II podem apresentar perda de peso e apetite seletivo; contudo, na presença de complicações da IRC, tais como pielonefrite e nefrolitíase, as manifestações clínicas podem se tornar mais evidentes. O estágio III é definido pela presença de azotemia em grau moderado (creatinina sérica entre $2,1-5,0 \mathrm{mg} / \mathrm{dL}$ para cães e de 2,9 - 5,0mg/dL para gatos). O paciente poderá apresentar manifestações sistêmicas da perda de função renal. A progressão da IRC nos pacientes nesse estágio geralmente está ligada aos mecanismos de progressão espontânea da doença (autoperpetuação), mas pode também se relacionar às causas desencadeantes. O estágio IV caracteriza-se pela presença de intensa azotemia (creatinina sérica superior a 5,0mg/dL para cães e gatos). Nesse estágio, o paciente apresenta importante perda da função renal que pode estar relacionada à falência renal e apresentar diversas manifestações sistêmicas da uremia como, por exemplo, alterações gastrintestinais, neuromusculares ou cardiovasculares.

As células progenitoras adultas multipotentes (CPAMs), também conhecidas na literatura como células-tronco mesenquimais, encontram-se presentes em um estado de quiescência em todos os tecidos que constituem o organismo. Sendo caraterizadas com base no seu potencial de autorenovação e diferenciação celular, as CPAMs são responsáveis por assegurar a homeostase do tecido durante o transcorrer da vida dos animais. As CPAMs apresentam um grande número de moléculas bioativas, que atuam modulando a resposta inflamatória, angiogênese e mitose das células envolvidas no processo de reparação tecidual. Quando introduzidas no organismo, adquirem tanto a morfologia como a funcionalidade de qualquer tipo celular que constitui o tecido lesionado (Caplan et al., 2015a; Caplan et al., 2015b).

Embora os mecanismos envolvidos na diferenciação das CPAMs in vivo ainda não tenham sido plenamente entendidos, sabe-se que estas 
atuam modificando o microambiente através da secreção de fatores parácrinos e/ou endócrinos, que potencializam a reparação tecidual, atribuindo-se o potencial reparativo à sua capacidade proliferativa, plasticidade, processos de sinalização celular, produção de biomoléculas, fatores de crescimento e moduladores da resposta imune (Murphy et al., 2013).

Dados experimentais em ratos sugeriram que a administração exógena das CPAMs durante as lesões renais crônica e aguda pode resultar em melhora funcional e recuperação estrutural a nível tubular, glomerular e intersticial dos rins. Para tal, as CPAMs são expostas a diferentes mecanismos de ação os quais incluem: a) liberação de fatores parácrinos e/ou endócrinos (Qin et al., 2012); b) estimulação do reparo endógeno pela atuação das CPAMs residentes no local lesado, as quais são estimuladas pela atividade parácrina das CPAMs exógenas (Dong e Caplan, 2012); c) fusão terapêutica, na qual as CPAMs se fusionam com células adultas diferenciadas, resultando em uma célula madura com o fenótipo desejado (Quijada et al., 2015) e d) incorporação das CPAMs ao tecido ou órgão danificado e sua diferenciação de forma a substituir as células lesionadas (Colletti et al., 2009).

Embora os mecanismos que levem as CPAMs a atuarem de forma protetora na lesão renal ainda não tenham sido esclarecidos, tem sido demonstrado claramente que as CPAMs são responsáveis pela mediação da angiogênese, supressão da inflamação e melhoria da função renal por meio da ação parácrina e/ou endócrina (Bussolati et al., 2008). Desta forma, as pesquisas envolvendo a utilização das células-tronco em doença renal se apresentam extremamente promissoras.

O objetivo deste estudo é descrever a eficácia do tratamento com CPAMs alogênicas derivadas de tecido adiposo de canino (CPAMsTAC) e expostas ao processo de criopreservação, na insuficiência renal crônica canina, estágio 2 , e a subsequente melhora na qualidade de vida dos pacientes.

\section{Material e Métodos}

\section{Seleção de Animais Doadores de tecido adiposo para o Tratamento Alogênico}

Os 12 cães foram selecionados a partir de populações de pacientes de clínicas veterinárias da cidade de São Paulo mediante consentimento livre e esclarecido por parte dos proprietários. As
CPAMs utilizadas no presente estudo foram obtidas a partir de cães jovens e saudáveis, com até seis meses de vida.

\section{Análise Molecular}

Foi colhida uma amostra de sangue para a análise da presença de herpes vírus canino (CHV), vírus da cinomose (CDV), Haemobartonella canis (HCA), Brucella sp. (BRU), Borrelia burgdorferi (BBU) e micoplasma através da amplificação de fragmentos dos respectivos genomas pelo método da reação em cadeia de polimerase (PCR) em materiais extraídos (RNA e DNA). Os RNAs foram extraídos com Trizol (Invitrogen) e utilizados para síntese de cDNA através de transcrição reversa com superscript II (Invitrogen). Os DNAs foram extraídos utilizando-se o DNAzol (Invitrogen). Reações positivas apresentam fragmentos de DNA de $183 \mathrm{pb}$ (CHV), $170 \mathrm{pb}$ (CDV), $341 \mathrm{pb}$ (HCA), $798 \mathrm{pb}$ (BRU), $287 \mathrm{pb}$ (BBU). Foram submetidas a cada pesquisa duas amostras extraídas, controles positivo e negativo.

\section{Isolamento e caracterização das CPAMs-TAC}

$\mathrm{O}$ tecido adiposo obtido no momento da castração dos cães foi lavado em 1x PBS de forma a retirar sangue e debris. Após a lavagem o tecido foi mantido durante 30 minutos a $37^{\circ} \mathrm{C} / 5 \%$ de $\mathrm{CO}_{2}$ em presença de $0,075 \%$ de colagenase tipo IV (Sigma). Foram adicionados $5 \mathrm{~mL}$ de meio basal sendo o sobrenadante retirado e centrifugado durante 5 minutos a $200 \mathrm{xg}$. O precipitado foi ressuspenso e transferido para uma garrafa de cultivo de $25 \mathrm{~cm}^{2}$, a qual foi mantida a $37^{0} \mathrm{C} / 5 \%$ $\mathrm{CO}_{2}$ durante 48 horas em presença de meio basal quando o mesmo foi trocado. Os repiques subsequentes foram feitos por meio de ação enzimática utilizando $0.025 \%$ de tripsina (Invitrogen). As CPAMs-TAC foram divididas em alíquotas de $2 \times 10^{6}$ células $/ \mathrm{mL}$, ressuspensas em meio de congelamento (10\% de DMSO, $70 \%$ de soro fetal bovino e $20 \%$ de meio basal) e armazenadas em nitrogênio líquido. As CPAMsTAC foram administradas com menos de 1 ano de armazenamento. Para serem aplicadas nos pacientes, as CPAMs-TAC foram descongeladas, em banho maria a $37^{\circ} \mathrm{C}$ por 2 minutos sendo adicionado 1x PBS na proporção de 1:1. O concentrado celular foi homogeneizado e centrifugado por 5 minutos a $200 \times \mathrm{g}$. $\mathrm{O}$ sobrenadante foi descartado sendo adicionado $1 \mathrm{x}$ PBS ao precipitado o qual foi homogeneizado e centrifugado por 5 minutos a $200 \times \mathrm{g}$. $\mathrm{O}$ 
procedimento foi realizado mais duas vezes sendo que ao final do último o precipitado celular foi ressuspenso em solução fisiológica para posterior infusão nos pacientes.

Para a análise proliferativa foi isolada uma colônia das CPAMs-TAC e expandida até atingir uma confluência de $70 \%$ em garrafa de cultivo de $25 \mathrm{~cm}^{2}$. As células foram removidas por meio de ação enzimática (tripsina $0.025 \%$, Invitrogen) e distribuídas em triplicatas sobre placas de $60 \mathrm{~cm}^{2}$ na concentração de $10^{5}$ células $/ \mathrm{mL}$. Após 48 horas, as células foram removidas e replaqueadas. $\mathrm{O}$ processo foi repetido até a $10^{\mathrm{a}}$ passagem. A viabilidade celular foi determinada por meio da análise por Trypan blue evidenciando uma taxa de 97\% de células viáveis.

O potencial osteogênico das CPAMs-TAC, na $5^{\text {a }}$ passagem, foi demonstrado por meio da coloração de Von Kossa, após as células terem sido mantidas em cultura durante 21 dias em presença do meio de diferenciação osteogênico composto por Dulbecco's Modified Eagle's Medium - Low Glucose (DMEM-LG; Invitrogen), $1 \%$ de $10^{-5} \mathrm{M}$ de dexametasona (Sigma), $1 \% \quad 5 \mathrm{mM}$ de ácido ascórbico (Sigma), 10\% de soro fetal bovino (FBS; HyClone, Logan, Utah) e $1 \%$ Streptomicina/Penicilina (Penicilina g $10.00 \mathrm{u} / \mathrm{mL}$, Streptomicina $10.000 \mathrm{mg} / \mathrm{mL}$; Invitrogen). A troca do meio foi feita a cada 3 ou 4 dias. No $10^{\circ}$ dia, foi adicionado $1 \%$ de $200 \mathrm{mM}$ de $\beta$-glicerolfosfato (Sigma). Para a análise do potencial de diferenciação adipogênico, as CPAMs-TAC, na $5^{\text {a }}$ passagem, foram cultivadas em meio de diferenciação adipogênico composto por Dulbecco's Modified Eagle's Medium - HIGH Glucose (DMEM-HG; Invitrogen), $10 \%$ de soro fetal bovino (FBS; HyClone, Logan, Utah), 1mM de dexametasona (Sigma), $100 \mathrm{mM}$ de endomentacina (Sigma), $0,5 \mathrm{M}$ de isobutilmetilxantina (Sigma), $10 \mu \mathrm{M}$ de insulina (Sigma) e $1 \%$ de antibiótico (Penicilina g $10.00 \mathrm{u} / \mathrm{mL}$, Streptomicina $10.000 \mathrm{mg} / \mathrm{mL}$; Invitrogen), durante 21 dias e marcadas com Oil Red $O$. O potencial de diferenciação condrogênico das CPAMs-TAC, na $5^{\text {a }}$ passagem, foi demonstrado por meio da marcação por azul de toluidina (Sigma), após as CPAMs-TAC terem sido cultivadas durante 21 dias em presença do meio de diferenciação condrogênico, composto por meio Dulbecco's Modified Eagle's Medium HIGH Glucose (DMEM-HG; Invitrogen) suplementado com $1 \%$ de soro fetal bovino (FBS; HyClone, Logan, Utah), 6,25mM de insulina
(Sigma), 0,1mM de dexametasona (Sigma), $1 \mathrm{mM}$ de piruvato de sódio (Invitrogen), 10ng/mL TGF$\beta 1$ (R\&D System, LGC Biotechnology) e 1\% de antibiótico (Penicilina g 10.00u/mL, Streptomicina $10.000 \mathrm{mg} / \mathrm{mL}$; Invitrogen).

A análise tumorgênica foi realizada em camundongos nude. Foram utilizados três animais, mantidos em ambiente estéril durante o período de 90 dias, os quais receberam a infusão de $2 \times 10^{6}$ CPAMs-TAC, na $5^{\text {a }}$ passagem, pela via intraperitoneal.

\section{Seleção de Animais para o Estudo}

Foram submetidos ao estudo piloto 12 cães (dois Maltês, um Pug, três sem raças definidas SRDs, dois Shih-Tzu, um Pequinês, dois LhasaApso e um Chihuahua), sendo oito machos e quatro fêmeas, com idades entre três anos e dois meses e 11 anos e cinco meses, pesando de $2 \mathrm{Kg}$ a $10 \mathrm{Kg}$, acometidos pela insuficiência renal crônica, estágio 2, segundo a IRIS (++)(Tabela 1).

Os pacientes para pré-tratamento foram avaliados por meio do perfil hepático (ALT e FA); função renal (ureia, creatinina, albumina, sódio, potássio e cálcio); hemograma; leucograma; radiografia torácica e ultrassonografia abdominal. Pacientes acometidos por neoplasmas, ureterolitíases, pielonefrite ou outro quadro infecioso, rim policístico ou outro tipo de possível massa tumoral, hipertensão, hipotensão ou com ureia acima de $180 \mathrm{mg} / \mathrm{dL}$ foram excluídos do estudo. Todos os pacientes apresentavam um quadro clínico e laboratorial estável há pelo menos duas semanas.

\section{Aplicação das CPAMs-TAC e monitoramento}

Os pacientes foram submetidos a três infusões de CPAMs-TAC alogênicas com intervalo médio de 30 dias entre cada uma. As aplicações foram realizadas pela via endovenosa, veia cefálica, sem que tenham sido submetidos à sedação. Foi utilizada a dose de $4 \times 10^{6}$ CPAMsTAC alogênicas. Os exames foram realizados anteriormente a cada uma das três aplicações e 180 dias após a terceira aplicação. Durante todo o processo a fluidoterapia foi mantida.

\section{Análise Estatística}

Os valores seriados tanto da creatinina como ureia dos cães submetidos às doses de CPAMsTAC, foram analisados estatisticamente por meio da ANOVA. Para tal, foi utilizado o software Prism5 (GraphPad, La Jolla, CA, USA). 


\section{Resultados e Discussão}

A terapia celular com células-tronco vem mostrando-se extremamente promissora no tratamento de diversas doenças. O tratamento visa, por meio de seus mecanismos de ação, curar e/ou melhorar a qualidade de vida de pacientes acometidos por diferentes doenças (Santos, 2017).

A IRC tem se mostrado a principal causa do aumento tanto da morbidade como da mortalidade em caninos, sendo o transplante renal, embora não seja uma opção viável para a maioria dos cães afetados, o único tratamento eficaz (Lim et al., 2016). Estudos realizados em roedores vêm sugerindo serem as CPAMs uma nova opção terapêutica para os caninos acometidos pela IRC (Samedo et al., 2009; Caldas et al., 2015). Quando administradas em roedores, as CPAMs têm ocasionado uma melhora da função renal, principalmente devido à redução da inflamação intra-renal e supressão da fibrose por meio de seu efeito parácrino (Samedo et al., 2009; Reinders et al., 2014).

No presente estudo, as CPAMs isoladas a partir do tecido adiposo de caninos jovens e saudáveis, foram caracterizadas com base em sua capacidade de adesão ao plástico, morfologia fibroblastoide (Figura 1), alto potencial de proliferação celular (Figura 2) e capacidade de diferenciação osteogênica (Figura 3A), adipogênica (Figura 3B) e condrogênica (Figura 3C). Quando injetadas em camundongos nude, as CPAMs-TAC não foram capazes de induzir a geração de teratocarcinomas. Tendo em vista se tratar de um tratamento alogênico, os pacientes doadores foram testados quanto à presença de CHV, CDV, HCA, BRU, BBU e micoplasma, não tendo sido detectada a presença dos respectivos patógenos evitando-se, desta forma, a possível transmissão aos animais receptores.

Os caninos submetidos à terapia com as CPAMs-TAC foram classificados, segundo a IRIS, como acometidos pelo estágio 2 da IRC (++). A análise bioquímica anterior ao início do tratamento revelou que os pacientes apresentavam valores de ureia entre $95 \mathrm{mg} / \mathrm{dL}$ e $174 \mathrm{mg} / \mathrm{dL}$ sendo os valores referência de $21 \mathrm{mg} / \mathrm{dL}$ à $60 \mathrm{mg} / \mathrm{dL}$ e creatinina de $1,53 \mathrm{mg} / \mathrm{dL}$ a $2,0 \mathrm{mg} / \mathrm{dL}$ com valores de referência de $0,5 \mathrm{mg} / \mathrm{dL}$ a $1,4 \mathrm{mg} / \mathrm{dL}$ (Kaneko et al., 1997) (Tabela 1). Todos os pacientes apresentavam quadro clínico e laboratorial estável há pelo menos duas semanas, sendo submetidos à infusão diária de $200 \mathrm{~mL}$ de ringer com lactato de sódio. Por se tratar de um estudo piloto com animais de proprietários, um grupo controle não foi incluído.

A via endovenosa se caracteriza por ser de fácil execução, pouco invasiva e menos traumática, permitindo repetidas aplicações com mínimos efeitos colaterais (Quimby et al., 2013). Além disso, estudos demonstram que a adminsitração das CPAMs pela via endovenosa tende a reduzir, por meio de seu efeito parácrino, a probabilidade da ocorrência de insuficiência renal aguda isquêmica (Zhang et al., 2016). Entretanto, quando administradas em altas concentrações, estudos sugerem a possível formação de tromboembolismo pulmonar (Moll et al., 2012).

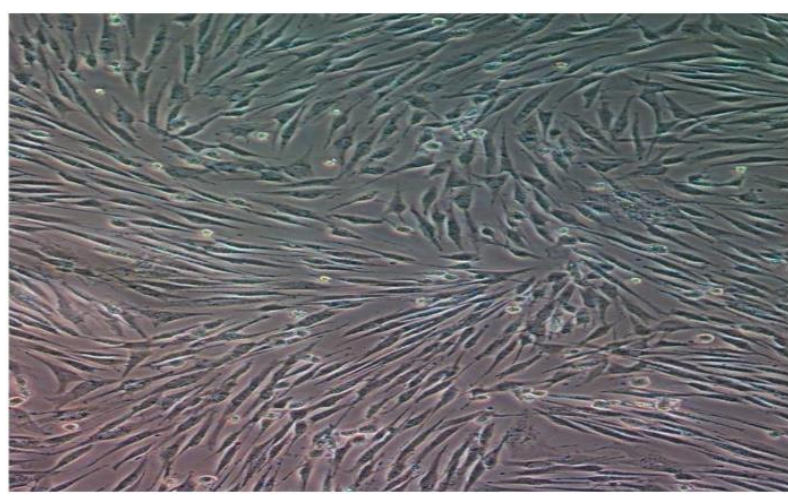

Figura 1. Aspecto morfológico fibroblastoide das células progenitoras adultas multipotentes isoladas a partir do tecido adiposo de cães (CPAMs-TAC). Objetiva 10x.

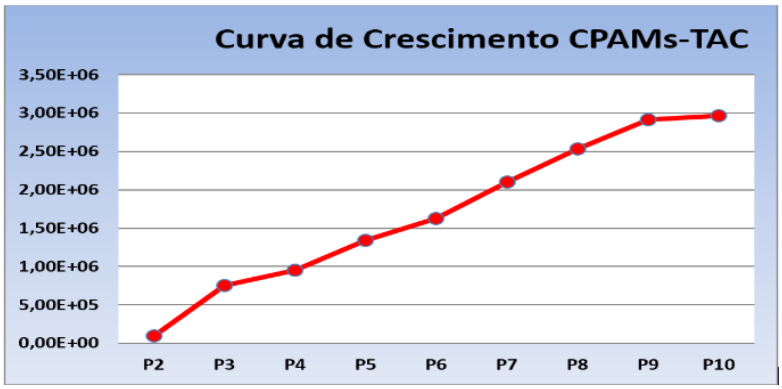

Figura 2. Gráfico representativo da analise proliferativa das CPAMs-TAC. O crescimento das células foi analisado em um intervalo de 48 horas entre os repiques realizados por meio de ação enzimática. Foi observado um crescimento exponencial até a 9a passagem, após a qual se identificou uma manutenção na curva de crescimento.

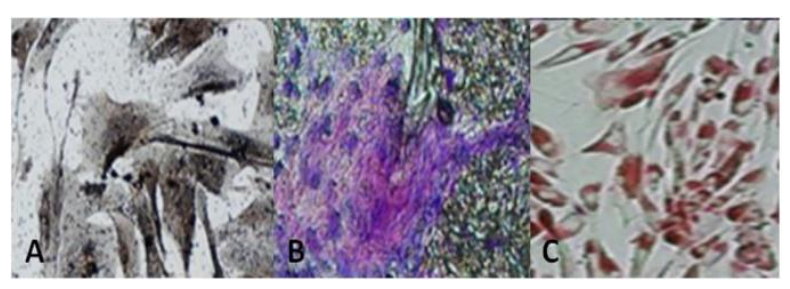

Figura 3. Imagens representativas das diferenciações osteogênicia (A), condrogênica (B) e adipogênicia (C) das CPAMs-TAC. Objetivas 20x (A,B) e 4x (C). 
Tabela 1. Dados representativos da variação de idade, raça, peso, índices séricos e ureia antes da primeira infusão das CPAMs-TAC, $4 \times 10^{6}$, pela via endovenosa. Todos os cães envolvidos no estudo foram classificados como IRIS 2. Inicialmente os animais apresentavam preso variando entre $2 \mathrm{~kg}$ e $10 \mathrm{~kg}$, idade entre 3 anos e 2 meses a 11 anos e 5 meses, valores séricos de creatinina entre $1,53 \mathrm{mg} / \mathrm{dL}$ e $2 \mathrm{mg} / \mathrm{dL}$ e ureia entre $95 \mathrm{mg} / \mathrm{dL}$ a 174 $\mathrm{mg} / \mathrm{dL}$.

\begin{tabular}{cccccccc}
\hline Cães & IRIS & Idade & Raça & Peso & Creatinina & Ureia & Via \\
Cão 1 & 2 & 3 anos & Maltês & $3 \mathrm{Kg}$ & $2,0 \mathrm{mg} / \mathrm{dL}$ & $172 \mathrm{mg} / \mathrm{dL}$ & Endovenosa \\
Cão 2 & 2 & 5 anos & Shih-Tzu & $6 \mathrm{Kg}$ & $2,0 \mathrm{mg} / \mathrm{dL}$ & $174 \mathrm{mg} / \mathrm{dL}$ & Endovenosa \\
Cão 3 & 2 & 3 anos & Maltes & $2 \mathrm{~kg}$ & $1,72 \mathrm{mg} / \mathrm{dL}$ & $105 \mathrm{mg} / \mathrm{dL}$ & Endovenosa \\
Cão 4 & 2 & 4 anos & SRD & $9 \mathrm{~kg}$ & $1,53 \mathrm{mg} / \mathrm{dL}$ & $97,75 \mathrm{mg} / \mathrm{dL}$ & Endovenosa \\
Cão 5 & 2 & 11 anos & Lhasa Apso & $5.5 \mathrm{~kg}$ & $1,81 \mathrm{mg} / \mathrm{dL}$ & $136,1 \mathrm{mg} / \mathrm{dL}$ & Endovenosa \\
Cão 6 & 2 & 8 anos & Lhasa Apso & $5 \mathrm{~kg}$ & $1,93 \mathrm{mg} / \mathrm{dL}$ & $163.48 \mathrm{mg} / \mathrm{dL}$ & Endovenosa \\
Cão 7 & 2 & 4 anos & Shih-Tzu & $6 \mathrm{Kg}$ & $2,0 \mathrm{mg} / \mathrm{dL}$ & $122 \mathrm{mg} / \mathrm{dL}$ & Endovenosa \\
Cão 8 & 2 & 7 anos & SRD & $10 \mathrm{Kg}$ & $1,91 \mathrm{mg} / \mathrm{dL}$ & $167,2 \mathrm{mg} / \mathrm{dL}$ & Endovenosa \\
Cão 9 & 2 & 9 anos & SRD & $9.5 \mathrm{Kg}$ & $1,70 \mathrm{mg} / \mathrm{dL}$ & $145 \mathrm{mg} / \mathrm{dL}$ & Endovenosa \\
Cão 10 & 2 & 6 anos & Pequinês & $4 \mathrm{Kg}$ & $1,97 \mathrm{mg} / \mathrm{dL}$ & $169 \mathrm{mg} / \mathrm{dL}$ & Endovenosa \\
Cão 11 & 2 & 5 anos & Pug & $7 \mathrm{Kg}$ & $1,83 \mathrm{mg} / \mathrm{dL}$ & $163 \mathrm{mg} / \mathrm{dL}$ & Endovenosa \\
Cão 12 & 2 & 3 anos & Chihuahua & $9 \mathrm{Kg}$ & $1,99 \mathrm{mg} / \mathrm{dL}$ & $172 \mathrm{mg} / \mathrm{dL}$ & Endovenosa \\
\hline
\end{tabular}

Os doze caninos foram submetidos a três infusões com doses de $4 \times 10^{6}$ de CPAMs-TAC alogênicas por meio da via endovenosa com intervalos de 30 dias. Estudos realizados em roedores evidenciaram a eficácia de múltiplas aplicações de CPAMs, visando tanto a supressão da fibrose como a inflamação intra-renal além de uma reparação tecidual mais efetiva (Samedo et al., 2009; Alexandre et al., 2009). Estes dados demonstram que repetidas infusões de CPAMsTAC alogênicas em baixas doses se apresentaram de forma simples, eficazes e seguras, uma vez que foram bem toleradas pelos animais.

Os resultados obtidos, por meio da adaptação do protocolo de roedores para caninos, sugerem que resultados similares poderão ser alcançados, embora algumas diferenças devam ser consideradas (Hensley et al., 2015). A infusão das CPAMs em ratos ocorre poucas semanas após a indução da lesão renal, ou seja, um período relativamente curto quando comparado ao processo natural dos cães, os quais possuem um período de vida mais extenso, podendo levar meses ou mesmo anos para que a DR possa ser diagnosticada (Samedo et al., 2009). Segundo, os resultados em roedores foram obtidos por meio da utilização das CPAMs autólogas, em detrimento às alogênicas aplicadas neste estudo. Estudos têm relatado dados controversos quanto à eficacia da terapia alógênica quando comparada a autóloga. Em ratos acometidos por falha renal aguda, os resultados obtidos utilizando as CPAMs autólogas foram mais efetivos, uma vez que os dados sugerem que as autólogas sobrevivem mais tempo no organismo quando comparada às alogênicas, resultando em uma menor efetividade destas (Tögel et al., 2009). Porém, em humanos, os estudos clínicos vêm utilizando frequentemente as CPAMs alogênicas (Tompkins et al., 2017; Hare et al., 2017). Terceiro, em nosso estudo, diferentemente dos estudos em roedores, foram utilizadas CPAMs alogênicas criopreservadas, dada a manutenção da funcionalidade e imunogenicidade das mesmas após serem expostas ao processo de criopreservação (Quimby et al., 2013).

Não foram identificados efeitos adversos nas infusões das CPAMs-TAC alogênicas como vômito, náusea, alteração da pressão arterial e/ou variação na frequência respiratória, demonstrando que o transplante é bem tolerado pelos cães. $\mathrm{O}$ acompanhamento dos pacientes não revelou a ocorrência de qualquer tipo de patologia associada à formação de tecido anormal. Estudos anteriores comprovaram que os tranplantes das CPAMs-TAC alogênicas têm se mostrado seguros com relação a rejeições, não requerendo a utilização de drogas imunosupressoras (Tögel et al., 2009; Reinders et al., 2015).

As CPAMs-TAC alogênicas foram administradas em baixas concentrações e lentamente, uma vez que estudos em ratos demonstram o risco de trombose pulmonar ou infartos quando uma elevada concentração celular é administrada rapidamente pela via endovenosa (Grigg et al., 1996; Prockop et al., 2007). Os dados referentes as análises laboratóriais dos pacientes não demonstraram variações estatisticamente relevantes nos volores de fósforo, albumina, sódio, potássio, cálcio assim como nos índices referentes ao hemograma. 
Durante o estudo foi observada uma redução nos valores séricos da creatinia até trinta dias após a terceira infusão das CPAMs-TAC tendo sido detectada uma leve elevação no valor nos índices do cão 5 (Figura 4). Nos noventa dias subsequentes observou-se uma estabilidade nos índices séricos da creatinina dos pacientes, embora os cães 2, 5, 9 e 10 tenham apresentado retornos ao valores próximos aos detectados no início do tratamento (Tabela 2). A análise dos valores séricos da ureia demonstrou uma redução em todos os animais até trinta dias após a terceira infusão das CPAMs-TAC (Figura 5). Nos noventa dias subsequentes foi observada uma estabilidade nos valores séricos da ureia dos animais embora os cães 1 e 10 tenham apresentado reduções consideráveis nos índices e o cão 2 tenha retornado ao valor próximo ao detectado no início do estudo (Tabela 3). Embora todos os pacientes tenham apresentado melhora logo após a primeira infusão de CPAMs-TAC, a qual permaneceu durante todo o estudo, apenas o cão 4 atingiu os valores séricos de creatinina, 1,37 $\mathrm{mg} / \mathrm{dL}$ e ureia $50,0 \mathrm{mg} / \mathrm{dL}$, que se situam dentro dos índices de normalidade. Ao término do estudo, todos os pacientes demonstravam um quadro de melhora na disposição física e alimentar, apresentando um comportamento clínico de animais saudáveis.

A análise estatística da ANOVA determinou uma redução estatisticamente significativa nos dados analisados referentes às taxas de creatinina $(\mathrm{P}=0,00000000000000001)$ e ureia $(\mathrm{P}=0,000000000000000002)$ demonstrando uma queda relevante nos valores. Todos os pacientes demonstraram uma significativa melhora da função renal após as infusões das CPAMs-TAC alogênicas sem aparentes efeitos adversos. Foi observada uma melhora clínica, aumento de apetite, ganho de peso e maior disposição em todos os pacientes já após a primeira aplicação. Ao término do estudo, os pacientes 1, 3, 4 e 12 estavam sendo submetidos a uma aplicação de fluidoterapia por semana, os cães $6,7,8$ e 11 estavam sendo submetidos à fluidoterapia duas vezes por semana e os cães 2,5 , 9 e 10 a cada dois dias.

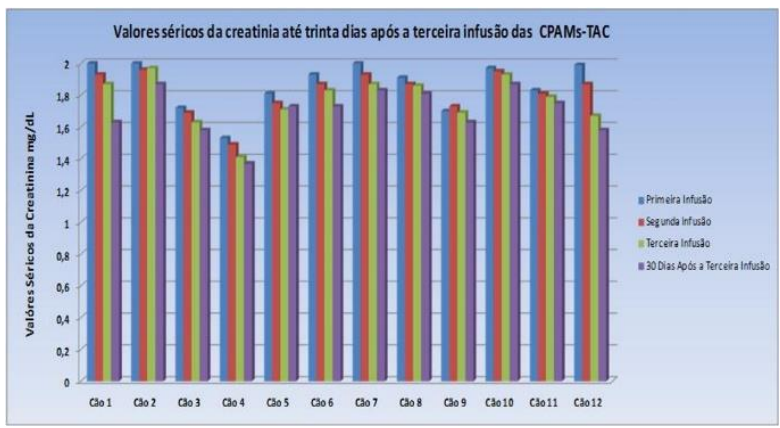

Figura 4. Análise dos valores séricos da creatinina dos caninos durante o transcorrer da aplicação das doses de CPAMs-TAC.

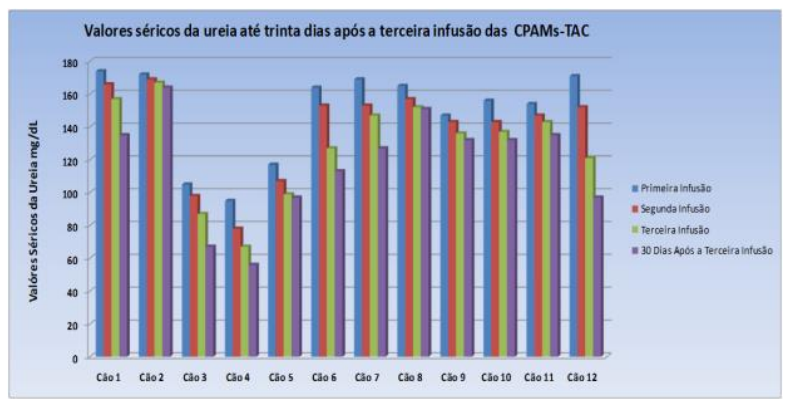

Figura 5. Análise dos valores séricos da ureia dos caninos durante o transcorrer da aplicação das doses de CPAMs-TAC.

Embora os resultados obtidos sejam de grande relevância, quanto à melhora clínica dos pacientes, os dados laboratoriais ainda carecem de melhoria. $\mathrm{O}$ fato dos estudos terem demonstrado resultados efetivos em ratos, quanto à utilização das CPAMs autólogas, uma vez que estas sobrevivem por mais tempo no organismo, sugere uma possível melhora nos indíces laboratoriais quanto à utilização das CPAMs autólogas, em detrimento das alogênicas (Tögel et al., 2009).

Tabela 2. Dados representativos das variações dos índices séricos de creatinina dos pacientes durante o período de 180 dias. Os pacientes receberam três doses de 4 × $10^{6}$ de CPAMs-TAC alogênicas por meio da via endovenosa. Durante o período de análise os índices séricos de creatinina variaram entre 1,53 mg/dL e $2 \mathrm{mg} / \mathrm{dL}$.

\begin{tabular}{ccccccccccccc}
\hline Dias & Cão1 & Cão2 & Cão3 & Cão4 & Cão5 & Cão6 & Cão7 & Cão8 & Cão9 & Cão10 & Cão11 & Cão12 \\
\hline $\mathbf{1}$ & 2,0 & 2,0 & 1,72 & 1,53 & 1,81 & 1,93 & 2,0 & 1,91 & 1,70 & 1,97 & 1,83 & 1,99 \\
$\mathbf{3 0}$ & 1,93 & 1,96 & 1,69 & 1,49 & 1,75 & 1,87 & 1,93 & 1,87 & 1,73 & 1,95 & 1,81 & 1,87 \\
$\mathbf{6 0}$ & 1,87 & 1,97 & 1,63 & 1,41 & 1,71 & 1,83 & 1,87 & 1,86 & 1,69 & 1,93 & 1,79 & 1,67 \\
$\mathbf{9 0}$ & 1,63 & 1,87 & 1,58 & 1,37 & 1,73 & 1,73 & 1,83 & 1,81 & 1,63 & 1,87 & 1,75 & 1,58 \\
$\mathbf{1 2 0}$ & 1,65 & 1,93 & 1,53 & 1,39 & 1,76 & 1,71 & 1,84 & 1,83 & 1,65 & 1,91 & 1,76 & 1,47 \\
$\mathbf{1 5 0}$ & 1,62 & 1,95 & 1,57 & 1,38 & 1,77 & 1,72 & 1,83 & 1,82 & 1,68 & 1,95 & 1,75 & 1,53 \\
$\mathbf{1 8 0}$ & 1,61 & 1,97 & 1,61 & 1,37 & 1,79 & 1,70 & 1,86 & 1,85 & 1,69 & 1,96 & 1,77 & 1,54 \\
\hline
\end{tabular}


Tabela 3. Dados representativos das variações dos índices séricos de ureia dos pacientes durante o período de 180 dias. Os pacientes receberam três doses de $4 \times 10^{6}$ de CPAMs-TAC alogênicas por meio da via endovenosa. Durante o período de análise os índices séricos de ureia variaram entre $50 \mathrm{mg} / \mathrm{dL}$ e $174 \mathrm{mg} / \mathrm{dL}$.

\begin{tabular}{ccccccccccccc}
\hline Dias & Cão1 & Cão2 & Cão3 & Cão4 & Cão5 & Cão6 & Cão7 & Cão8 & Cão9 & Cão10 & Cão11 & Cão12 \\
\hline $\mathbf{1}$ & 174 & 172 & 105 & 95 & 117 & 164 & 169 & 165 & 147 & 156 & 154 & 171 \\
$\mathbf{3 0}$ & 166 & 169 & 98 & 78 & 107 & 153 & 153 & 157 & 143 & 143 & 147 & 152 \\
$\mathbf{6 0}$ & 157 & 167 & 87 & 67 & 99 & 127 & 147 & 152 & 136 & 137 & 143 & 121 \\
$\mathbf{9 0}$ & 135 & 164 & 67 & 56 & 97 & 113 & 127 & 151 & 132 & 132 & 135 & 97 \\
$\mathbf{1 2 0}$ & 132 & 168 & 68 & 53 & 109 & 98 & 129 & 154 & 136 & 136 & 132 & 89 \\
$\mathbf{1 5 0}$ & 129 & 169 & 70 & 52 & 110 & 100 & 127 & 153 & 134 & 136 & 131 & 79 \\
$\mathbf{1 8 0}$ & 117 & 170 & 69 & 50 & 113 & 101 & 132 & 156 & 133 & 138 & 129 & 74 \\
\hline
\end{tabular}

\section{Conclusão}

Os resultados do presente estudo são pioneiros ao demonstrar que a aplicação subsequente pela via endovenosa das células progenitoras adultas multipotentes alogênicas previamente criopreservadas, isoladas a partir do tecido adiposo de caninos jovens e clinicamente saudáveis, resulta em uma significativa melhora na qualidade de vida dos pacientes acometidos pela insuficiencia renal crônica, estágio 2.

\section{Conflito de Interesse}

Os autores declaram não existir conflito de interesse.

\section{Comitê de Ética}

$\mathrm{O}$ projeto de pesquisa foi aprovado pelo comitê de ética da CELLTROVET, sob o número $1 / 2017$.

\section{Referências}

Alexandre, C.S.; Volpini, R.A.; Shimizu, M.H.; Sanches, T.R.; Semedo, P.; di Jura, V.L.; Câmara, N.O.; Seguro, A.C.; Andrade, L. Lineage-negative bone marrow cells protect against chronic renal failure. Stem Cells, 27(3): 682-692, 2009.

Barber, P. Diagnosis and management of chronic renal failure in the cat. In Practice, 25(6): 306313, 2003.

Bussolati, B.; Tetta, C.; Camussi, G. Contribution of stem cells to kidney repair. American Journal of Nephrology, 28(5): 813-22, 2008.

Caldas, H.C.; de Paula Couto, T.A.; Fernandes, I.M.; Baptista, M.A.; Kawasaki-Oyama, R.S.; Goloni-Bertollo, E.M.; Braile, D.M.; AbbudFilho, M. Comparative effects of mesenchymal stem cell therapy in distinct stages of chronic renal failure. Clinical and Experimental Nephrology, 19(5): 783-9, 2015.

Caplan, A.I.; Sorrell, J.M. The MSC curtain that stops the immune system. Immunology Letters, 168(2): 136-9, 2015a.
Caplan, A.I.; Hariri, R. Body Management: Mesenchymal Stem Cells Control the Internal Regenerator. Stem Cells Translational Medicine, 4(7): 695-701, 2015 b.

Castro, M.C.N. Prolongando a vida do paciente com insuficiência renal crônica. Clínica Veterinária, 58: 50-58, 2005.

Colletti, E.J.; Airey, J.A.; Liu, W.; Simmons, P.J.; Zanjani, E.D.; Porada, C.D.; Almeida-Porada, G. Generation of tissue-specific cells from MSC does not require fusion or donor-to-host mitochondrial/membrane transfer. Stem Cell Research, 2(2): 125-38, 2009.

Dong, F.; Caplan, A.I. Cell transplantation as an initiator of endogenous stem cell-based tissue repair. Current Opinion in Organ Transplantation, 17(6): 670-4, 2012.

Etiinger, J.S.; Feldman, E.C.; Cote, E. Insuficiência renal crônica. In: ___ Textbook of veterinary internal medicine: diseases of the dog and the cat. $8^{\text {th }}$ ed. Saint. Louis, Mo.: Elsevier Saunders, 2017. p.1822-1872.

Grauer, G.F. Early detection of renal damage and disease in dogs and cats. The Veterinary Clinics of North America. Small Animal Practice, 35(3): 581-96, 2005.

Grigg, A.; Gibson, R.; Bardy, P.; Szer, J. Acute portal vein thrombosis after autologous stem cell transplantation. Bone Marrow Transplantation, 18(5): 949-53, 1996.

Hare, J.M.; DiFede, D.L.; Rieger, A.C.; Florea, V.; Landin, A.M.; El-Khorazaty, J.; Khan, A.; Mushtaq, M.; Lowery, M.H.; Byrnes, J.J.; Hendel, R.C.; Cohen, M.G.; Alfonso, C.E.; Valasaki, K.; Pujol, M.V.; Golpanian, S.; Ghersin, E.; Fishman, J.E.; Pattany, P.; Gomes, S.A.; Delgado, C.; Miki, R.; Abuzeid, F.; VidroCasiano, M.; Premer, C.; Medina, A.; Porras, V.; Hatzistergos, K.E.; Anderson, E.; Mendizabal, A.; Mitrani, R.; Heldman, A.W. Randomized comparison of allogeneic versus autologous mesenchymal stem cells for nonischemic dilated cardiomyopathy: 
poseidon-dcm trial. Journal of The American College of Cardiology, 69(5): 526-537, 2017.

Hensley, M.T.; de Andrade, J.; Keene, B.; Meurs, K.; Tang, J.; Wang, Z.; Caranasos, T.G.; Piedrahita, J.; Li, T.S.; Cheng, K. Cardiac regenerative potential of cardiosphere-derived cells from adult dog hearts. Journal of Cellular and Molecular Medicine, 19(8): 1805-13, 2015.

Kaneko, J.J.; Harvey, J.W.; Bruss, M. Appendixes.In: __. Clinical biochemistry of domestic animals. $4^{\text {th }}$ ed. San Diego: Academic Press, 1997. p.903.

Lim, C.Y.; Han, J.I.; Kim, S.G.; Lee, C.M.; Park, H.M. Evaluation of autologous bone marrowderived mesenchymal stem cells on renal regeneration after experimentally induced acute kidney injury in dogs. American Journal of Veterinary Research, 77(2): 208-17, 2016.

McGrotty, Y. Diagnosis and management of chronic kidney disease in dogs and cats. In Practice, 30: 502-507, 2008.

Moll, G.; Rasmusson-Duprez, I.; Von Bahr, L.; Connolly-Andersen, A.M.; Elgue, G.; Funke, L.; Hamad, O.A.; Lönnies, H.; Magnusson, P.U.; Sanchez, J.; Teramura, Y.; NilssonEkdahl, K.; Ringdén, O.; Korsgren, O.; Nilsson, B.; Le Blanc, K. Are therapeutic human mesenchymal stromal cells compatible with human blood? Stem Cells, 30(7): 1565-74, 2012.

Murphy, M.B.; Moncivais, K.; Caplan, A.I. Mesenchymal stem cells: environmentally responsive therapeutics for regenerative medicine. Experimental \& Molecular Medicine, 45: e54, 2013.

Pressler, B.M. Clinical approach to advanced renal function testing in $\operatorname{dogs}$ and cats. The Veterinary Clinics of North America. Small Animal Practice, 43(6): 1193-208, 2013.

Prockop, D.J.; Olson, S.D. Clinical trials with adult stem/progenitor cells for tissue repair: Let's not overlook some essential precautions. Blood, 109(8): 3147-51, 2007.

Qin, Z.H.; Xu, J.F.; Qu, J.M.; Zhang, J.; Sai, Y.; Chen, C.M.; Wu, L.; Yu, L. Intrapleural delivery of MSCs attenuates acute lung injury by paracrine/endocrine mechanism. Journal of Cellular and Molecular Medicine, 16(11): 2745-53, 2012.

Quijada, P.; Salunga, H.T.; Hariharan, N.; Cubillo, J.D.; El-Sayed, F.G.; Moshref, M.; Bala, K.M.; Emathinger, J.M.; De La Torre, A.; Ormachea,
L.; Alvarez, R.Jr.; Gude, N.A.; Sussman, M.A. Cardiac stem cell hybrids enhance myocardial repair. Circulation Research, 117(8): 695-706, 2015.

Quimby, J.M.; Webb, T.L.; Habenicht, L.M.; Dow, S.W. Safety and efficacy of intravenous infusion of allogeneic cryopreserved mesenchymal stem cells for treatment of chronic kidney disease in cats: results of three sequential pilot studies. Stem Cell Researchand Therapy, 4(2): 48, 2013.

Reinders, M.E.; de Fijter, J.W.; Rabelink, T.J. Mesenchymal stromal cells to prevent fibrosis in kidney transplantation. Current Opinion in Organ Transplantation, 19(1): 54-9, 2014.

Reinders, M.E.; Dreyer, G.J.; Bank, J.R.; Roelofs, H.; Heidt, S.; Roelen, D.L.; Zandvliet, M.L.; Huurman, V.A.; Fibbe, W.E.; van Kooten, C.; Claas, F.H.; Rabelink, T.J.; de Fijter, J.W. Safety of allogeneic bone marrow derived mesenchymal stromal cell therapy in renal transplant recipients: The neptune study. Journal of Translational Medicine, 13: 344, 2015.

Santos, E.J.C. Análise da Aplicação Terapêutica das Células Tronco na Medicina Veterinária. Revista Científica Multidisciplinar Núcleo do Conhecimento, 1: 269-295, 2017.

Semedo, P.; Correa-Costa, M.; Cenedeze, M.A.; Malheiros, D.M.A.C.; Reis, M.A.; Shimizu, M.H.; Seguro, A.C.; Pacheco-Silva, A.; Saraiva Camara, N.O. Mesenchymal stem cells attenuate renal fibrosis through immune modulation and remodeling properties in a rat remnant kidney model. Stem Cells, 27(12): 3063-73, 2009.

Tögel, F.; Cohen, A.; Zhang, P.; Yang, Y.; Hu, Z.; Westenfelder, C. Autologous and allogeneic marrow stromal cells are safe and effective for the treatment of acute kidney injury. Stem Cells and Development, 18(3): 475-85, 2009.

Tompkins, B.A.; DiFede, D.L.; Khan, A.; Landin, A.M.; Schulman, I.H.; Pujol, M.V.; Heldman, A.W.; Miki, R.; Goldschmidt-Clermont, P.J.; Goldstein, B.J.; Mushtaq, M.; Levis-Dusseau, S.; Byrnes, J.J.; Lowery, M.; Natsumeda, M.; Delgado, C.; Saltzman, R.; Vidro-Casiano, M.; Da Fonseca, M.; Golpanian, S.; Premer, C.; Medina, A.; Valasaki, K.; Florea, V.; Anderson, E.; El-Khorazaty, J.; Mendizabal, A.; Green, G.; Oliva, A.A.; Hare, J.M. Allogeneic mesenchymal stem cells ameliorate aging frailty: a phase II randomized, double-blind, 
placebo-controlled clinical trial. The Journals of Gerontology. Series A, Biological Sciences and Medical Sciences, 72(11): 1513-1522, 2017.

Zhang, G.; Zou, X.; Huang, Y.; Wang, F.; Miao, S.;

Liu, G.; Chen, M.; Zhu, Y. Mesenchymal stromal cell derived extracellular vesicles protect against acute kidney injury through antioxidation by enhancing nrf2/are activation in rats. Kidney and Blood Pressure Research, 41(2): 119-28, 2016. 